\title{
Prolonged prone positioning under VV-ECMO is safe and improves oxygenation and respiratory compliance
}

Antoine Kimmoun 1,2,3, Sylvain Roche ${ }^{1}$, Céline Bridey ${ }^{1}$, Fabrice Vanhuyse ${ }^{2,3,5}$, Renaud Fay ${ }^{6}$, Nicolas Girerd ${ }^{6}$, Damien Mandry ${ }^{3,4}$ and Bruno Levy $1,2,3^{*}$

\begin{abstract}
Background: Data are sparse regarding the effects of prolonged prone positioning (PP) during VV-ECMO. Previous studies, using short sessions ( $<12 \mathrm{~h}$ ), failed to find any effects on respiratory system compliance. In the present analysis, the effects of prolonged PP sessions ( $24 \mathrm{~h}$ ) were retrospectively studied with regard to safety data, oxygenation and respiratory system compliance.

Methods: Retrospective review of 17 consecutive patients who required both VV-ECMO and prone positioning. PP under $\mathrm{V}$-ECMO was considered when the patient presented at least one unsuccessful ECMO weaning attempt after day 7 or refractory hypoxemia combined or not with persistent high plateau pressure. PP sessions had a duration of $24 \mathrm{~h}$ with fixed ECMO and respiratory settings. PP was not performed in patients under vasopressor treatment and in cases of recent open chest cardiac surgery.

Results: Despite optimized protective mechanical ventilation and other adjuvant treatment (i.e. PP, inhaled nitric oxide, recruitment maneuvers), 44 patients received $\mathrm{W}$-ECMO during the study period for refractory acute respiratory distress syndrome. Global survival rate was $66 \%$. Among the latter, 17 patients underwent PP during VV-ECMO for a total of 27 sessions. After $24 \mathrm{~h}$ in prone position, $\mathrm{PaO}_{2} / \mathrm{FiO}_{2}$ ratio significantly increased from 111 (84-128) to 173 (120203) $\mathrm{mmHg}(p<0.0001)$ while respiratory system compliance increased from $18(12-36)$ to $32(15-36) \mathrm{ml} / \mathrm{cmH}_{2} \mathrm{O}$ $(p<0.0001)$. Twenty-four hours after the return to supine position, tidal volume was increased from $3.0(2.2-4.0)$ to 3.7 $(2.8-5.0) \mathrm{ml} / \mathrm{kg}(p<0.005) . \mathrm{PaO}_{2} / \mathrm{FiO}_{2}$ ratio increased by over $20 \%$ in $14 / 14$ sessions for late sessions $(\geq 7$ days) and in $7 / 13$ sessions for early sessions ( $<7$ days) $(p=0.01)$. Quantitative $C T$ scan revealed a high percentage of non-aerated or poorly-aerated lung parenchyma [52 \% (41-62)] in all patients. No correlation was found between CT scan data and respiratory parameter changes. Hemodynamics did not vary and side effects were rare (one membrane thrombosis and one drop in ECMO blood flow).
\end{abstract}

Conclusion: When used in combination with $\mathrm{V}$-ECMO, $24 \mathrm{~h}$ of prone positioning improves both oxygenation and respiratory system compliance. Moreover, our study confirms the absence of serious adverse events.

Keywords: ARDS, ECMO, Prone positioning

\section{Background}

One year after the publication of the PROSEVA study, the association of prone positioning (PP) and lung-protective

\footnotetext{
*Correspondence: b.levy@chu-nancy.fr

${ }^{1}$ CHU Nancy, Service de Réanimation Médicale Brabois, Pole Cardiovasculaire et Réanimation Médicale, Hôpital Brabois, 54511 Vandoeuvre les Nancy, France

Full list of author information is available at the end of the article
}

ventilation has become routine management for patients with acute respiratory distress syndrome (ARDS) [1]. However, refractory ARDS is still observed in all recent observational and randomized trials [1-3]. In these cases, veno-venous extra-corporeal membrane oxygenation (VV-ECMO) is indicated while awaiting lung function recovery [4]. Indeed, in the CESAR trial, a protocol including VV-ECMO was associated with a decreased 
mortality rate when compared to a conventional lung protective strategy [2].

The management of persistent severe hypoxemia under VV-ECMO requires a multi-step clinical approach including the optimization of VV-ECMO blood flow, red blood cell transfusion, moderate hypothermia, optimization of native lung function, short-action beta-blockers and finally PP [5]. PP can be effective in patients with VV-ECMO given that the use of ultra-protective ventilation [i.e. $3-4 \mathrm{~mL} / \mathrm{kg} \mathrm{Vt}$ ] may increase the proportion of poorly-aerated areas in dependent lung regions [6]. As a result, PP during VV-ECMO may recruit the dorsal regions of the lungs, facilitate lung drainage and therefore improve oxygenation. The value of PP during VV-ECMO has furthermore been previously described in a few studies, the largest being a study by Guervilly et al. in which $12 \mathrm{~h}$ of PP significantly improved the $\mathrm{PaO}_{2} / \mathrm{FiO}_{2}$ ratio in 15 ARDS patients on VV-ECMO after a median of 9 days [7]. Altogether, data from this and other previously published studies suggest that PP during VV-ECMO is safe when performed by a referent team and ultimately improves oxygenation. Of note, these studies failed to find any improvement in respiratory system compliance [6-11].

Since PP during VV-ECMO also carries potentially harmful effects, it is thus imperative to better delineate its effects and putative indications.

Previous studies, using short sessions $(>12 \mathrm{~h})$, failed to find any effects on respiratory system compliance. In light of the above, the present study was aimed at retrospectively analyzing the effects of prolonged PP sessions ( $24 \mathrm{~h}$ ) on safety data, oxygenation and respiratory system compliance.

\section{Methods}

The ECMO database of our 14-bed ICU was retrospectively reviewed to identify patients who received PP during VV-ECMO between January 2012 (first treatment in our ICU) and January 2014. The study protocol was evaluated by the local Ethics Committee (Comite de Réflexion Ethique Nanceien Hospitalo-Universitaire) which waived written informed consent due to both the retrospective study design and because PP and VV-ECMO are an integral part of care provided to patients with ARDS. All patients or their relatives were informed that some data could be used for clinical research. We included patients with severe ARDS as defined by the BERLIN consensus [12].

\section{ARDS management}

All patients were treated in accordance with the latest recommended guidelines. In particular, treatment in ICU included the systematic use of protective ventilation, transient use of paralyzing agents, diuresis to dry weight, prone positioning, recruitment maneuvers, transient use of inhaled nitric oxide and high positive end expiratory pressure (PEEP) levels [2].

\section{Indication of ECMO}

VV-ECMO was considered in patients with an optimal protective ventilator setting (Vt at $6 \mathrm{~mL} / \mathrm{kg}$ of predicted body weight, PEEP adjusted to maintain a plateau pressure (pPlat) between 27 and $30 \mathrm{cmH}_{2} \mathrm{O}$ ) after the failure of at least one prone positioning session with one of the following criteria adapted from the ongoing EOLIA trial: (1) $\mathrm{PaO}_{2} / \mathrm{FiO}_{2}<50 \mathrm{mmHg}$ for more than $3 \mathrm{~h}$ under $\mathrm{FiO}_{2}>80 \%$; (2) $\mathrm{PaO}_{2} / \mathrm{FiO}_{2}<85 \mathrm{mmHg}$ for more than $6 \mathrm{~h}$; (3) pPlat $>35 \mathrm{cmH}_{2} \mathrm{O}$ despite adjustment of $V t$ and PEEP; (4) $\mathrm{pH}<7.25$ for more than $6 \mathrm{~h}$ despite an increase in respiratory rate to $35 / \mathrm{min}$. VV-ECMO was either initiated in our intensive care unit (ICU) or in another hospital. In the latter instance, all patients were transferred to our ICU immediately after instituting VV-ECMO by our mobile ECMO team.

\section{ECMO management}

All VV-ECMOs were performed using percutaneous cannulation under echocardiography. A femorojugular circuit was implanted whenever possible, with femoro-femoral jugular circuit as an alternative. A servo-controlled centrifugal pump (Rotaflow console, Maquet, Hirrlingen, Germany) and poly-methyl pentene oxygenators (Quadrox Bioline oxygenator system Maquet, Hirrlingen, Germany) were used. The circuit and the oxygenator were fully coated with heparin. VV-ECMO flow was adapted daily according to cardiac output measured by echocardiography in order to maintain an ECMO blood flow/cardiac output ratio of at least 0.7 [13]. Sweep gas flow was titrated in order to maintain $\mathrm{PaCO}_{2}$ between 40 and $45 \mathrm{mmHg}$. Oxygen fraction delivered on the membrane $\left(\mathrm{FDO}_{2}\right)$ was adjusted on post-oxygenator blood gas. Heparin was continuously infused to obtain an anti-Xa activity at $0.1-0.2$.

\section{Respiratory management under VV-ECMO}

All patients were ventilated in volume control mode. Ultraprotective ventilation was applied during the first $48 \mathrm{~h}$ with the following settings: Vt at $1.5-3 \mathrm{ml} / \mathrm{kg}$ of predicted body weight, respiratory rate between 8 and $12 / \mathrm{min}$, PEEP between 10 and 18 adapted for a pPlat at $25 \mathrm{cmH}_{2} \mathrm{O} . \mathrm{FiO}_{2}$ was adapted for a $\mathrm{SpO}_{2}$ between 88 and $95 \%$. All patients were sedated and paralyzed by besilate cisatracurium (Hospira France, France) during the first $24 \mathrm{~h}$. After $24 \mathrm{~h}$, besilate cisatracurium was discontinued when possible. 


\section{Weaning procedure}

After the first $48 \mathrm{~h}$, Vt was increased daily when possible, respecting a pPlat at $25 \mathrm{cmH}_{2} \mathrm{O}$. When Vt was $>5 \mathrm{ml} / \mathrm{kg}$ of predicted body weight and respiratory rate $>15 / \mathrm{min}$, ECMO and sweep gas flow were progressively decreased respecting the following criteria: (1) $\mathrm{PaO}_{2} /$ $\mathrm{FIO}_{2}>150 \mathrm{mmHg}$, (2) $\mathrm{FiO}_{2}$ on ventilator $<60 \%$, (3) $\mathrm{PaCO}_{2}<50 \mathrm{mmHg}$, (4) pPlat $<25 \mathrm{cmH}_{2} \mathrm{O}$. ECMO was halted if the above criteria were respected in a non paralyzed patient after a successful 12-24 h session with a sweep gas flow at $0 \mathrm{~L} / \mathrm{min}$.

\section{Indication for prone positioning under VV-ECMO}

Prone positioning placement was only performed in one of the two following conditions: (1) Failure of attempts to wean VV-ECMO after at least 7 days under VV-ECMO combined with the need of therapeutic sedation, (2) Refractory hypoxemia with $\mathrm{PaO}_{2} / \mathrm{FiO}_{2}$ ratio $<85 \mathrm{mmHg}$ under $\mathrm{FiO}_{2} 100 \%$ both on the ventilator and the membrane despite optimal VV-ECMO and ventilator settings combined or not with persistent high plateau pressure $\left(>25 \mathrm{cmH}_{2} \mathrm{O}\right)$ despite ultra-protective ventilation. Further sessions were also performed according to the same indications.

\section{Contraindication for placement in prone position under VV-ECMO}

Given the potential risks of PP during VV-ECMO, PP was not performed in patients under vasopressor treatment and in cases of recent open chest cardiac surgery. PP was proposed only in patients who were still under sedation and in whom it was not possible to use partial ventilatory support.

\section{Protocol for prone positioning under VV-ECMO (Additional files 1, 2)}

The protocol was adapted from PROSEVA guidelines for prone positioning placement and has been published elsewhere $[1,6]$. The detailed protocol is described in the supplementary material.

\section{Study parameters}

The use of PP in our ICU with or without ECMO is described in an institutional procedure. For all sessions, parameters were recorded at three time intervals: prior to prone positioning placement, after $24 \mathrm{~h}$ in prone position and $24 \mathrm{~h}$ after the return to supine position. As specified in the procedure, in order to formally objectify respiratory improvement, respiratory and VV-ECMO parameters were maintained constant throughout the entire prone positioning session. An increase in $\mathrm{FiO}_{2}$ and/or VV-ECMO blood flow was only considered when $\mathrm{SpO}_{2}$ was below $85 \%$. VV-ECMO and ventilator settings were adjusted according to lung recovery after the prone positioning session. Data analysis also included the recording, at the above three pre-specified times, of complete blood gas $\left(\mathrm{PaO}_{2}, \mathrm{PaCO}_{2}, \mathrm{pH}, \mathrm{HCO}_{3}^{-}, \mathrm{SaO}_{2}\right)$, respiratory parameters (respiratory rate, $\mathrm{Vt}, \mathrm{PEEP}, \mathrm{FiO}_{2}$, pPlat, respiratory system compliance) and VV-ECMO parameters (blood flow, sweep gas flow, oxygen delivery by VVECMO device: $\mathrm{FDO}_{2}$ ). Respiratory system compliance (RS compliance) was computed by dividing tidal volume by pPlat (measured during an end-inspiratory pause ( $1 \mathrm{~s}$ ) minus total PEEP. Total PEEP was measured by using an expiratory pause $(5 \mathrm{~s})$. Driving pressure was calculated as plateau pressure minus PEEP [14]. The pre-ECMO survival probability was also calculated according to the RESP score [15].

\section{Chest $\mathrm{CT}$ analysis}

In patients who underwent a computed tomography (CT) scan within the 3 days prior to placement in prone position, a measurement of the amount of non-aerated lung tissue was performed according to an adapted previously-published method by Malbouisson et al. [16]. The detailed protocol is presented in the Additional file 3 (see Figure S1) [17].

\section{Adverse effects}

Three categories were systematically reported in the procedure: (1) adverse effects related to the cannulas and VV-ECMO device during the prone position session (drop in flow necessitating fluid resuscitation, oxygenator thrombosis, cannula removal, bleeding from cannulation sites), (2) adverse effects related to the tracheal tube and the ventilator device (accidental tracheal extubation, tube displacement) and (3) adverse effects related to the other catheters (accidental wrenching of central venous or arterial lines and nasogastric tube).

\section{Statistical analysis}

All analyses were performed using SAS software R9.3 (SAS Institute, Cary, NC, USA). The two-tailed significance level was set at $p<0.05$. Results are respectively presented as median (1st-3rd quartiles) and frequency (percentage) for continuous and discrete variables. The paired Wilcoxon test and Fisher's exact test were carried out for intra-group (before-after PP) and inter-group (respiratory response) comparisons, respectively. Since 11 intra-group comparisons were performed on the same subjects at the end of each session and $24 \mathrm{~h}$ thereafter, significance levels were adjusted for multiple testing at each respective time points. Results were analyzed for the first session $(n=17)$ as well as for all sessions $(n=27)$, considering that the increase in gas exchange of a given PP session does not predict survival [18]. Moreover, the 
sampling and the number of sessions did not allow for any intra-individual adjustment.

\section{Results}

\section{Population description (Table 1)}

Despite optimized protective mechanical ventilation and other adjuvant treatment (i.e. PP, inhaled nitric oxide, recruitment maneuvers), 44 patients received VV-ECMO during the study period for refractory acute respiratory distress syndrome. Global survival rate was $66 \%$. Among the latter, 17 patients underwent PP during VV-ECMO. Pre-ECMO survival probability according to the RESP score was $76 \%$ (33-90). All of the patients had a severe ARDS according to the Berlin definition [19]. Before being placed on VV-ECMO, 13/17 (76 \%) patients were prone positioned. Prior to ECMO implantation, 4/14 patients previously responded to PP in terms of oxygenation but developed major respiratory acidosis and high plateau pressure. Femoro-jugular VV-ECMO was used in 16/17 patients and femoro-femoral VV-ECMO in one patient. ARDS was related to an infectious process in all

Table 1 Baseline characteristics

\begin{tabular}{ll}
\hline & $\begin{array}{l}\text { Median (quartiles) or } \\
\boldsymbol{n}(\%), \boldsymbol{n}=17\end{array}$ \\
\hline Age (years) & $45(36-55)$ \\
Male gender & $12 / 17(71 \%)$ \\
Body mass index (kg/m $\left.{ }^{2}\right)$ & $27(23-34)$ \\
SAPS II score & $44(38-59)$ \\
SOFA score (at ICU admission) & $12(8-15)$ \\
SOFA score (before first PP session) & $7(5-11)$ \\
Pre-existing conditions & \\
Congestive heart failure & $2 / 17(12 \%)$ \\
Neoplasia & $0 / 17$ \\
Chronic respiratory disorders & $1 / 17(6 \%)$ \\
Neuropsychiatric disorders & $4 / 17(24 \%)$ \\
None & $10 / 17(59 \%)$ \\
Causes of ARDS & \\
Gram-negative pneumonia & $7 / 17(41 \%)$ \\
Gram-positive pneumonia & $8 / 17(47 \%)$ \\
Influenza virus & $4 / 17(24 \%)$ \\
Abdominal septic shock & $2 / 17(12 \%)$ \\
Sarcoidosis & $1 / 17(6 \%)$ \\
Prone positioning before ECMO & $13 / 17(76 \%)$ \\
Pre-ECMO survival probability (\%) (RESP score) & $76(33-90)$ \\
Duration of hospitalization before ICU (days) & $1(1-2)$ \\
Duration under ECMO (days) & $18(13-26)$ \\
Duration of ICU stay (days) & $54(36-66)$ \\
Survival at discharge & $16 / 17(94 \%)$ \\
\hline SAPSII sinplise & \\
\hline &
\end{tabular}

SAPS // simplified acute physiology score II, SOFA sequential organ failure assessment, $A R D S$ acute respiratory distress syndrome, ECMO extracorporeal membrane oxygenation, ICU intensive care unit cases. Four patients presented an influenza infection at admission.

Prone positioning was considered after a median delay of 6 days of VV-ECMO (4-12). Sixteen of 27 prone position sessions were performed after this median period. Indications for PP included unsuccessful VV-ECMO weaning attempts after at least 7 days under VV-ECMO in $11 / 17$ patients and refractory hypoxemia with $\mathrm{PaO}_{2} /$ $\mathrm{FiO}_{2}$ ratio $<85 \mathrm{mmHg}$ despite optimal $\mathrm{VV}$-ECMO and ventilator settings in $6 / 17$ patients. For three patients (6 sessions), refractory hypoxemia was associated with elevated plateau pressure despite ultra-protective ventilation. Four patients had 3 sessions and two patients had 2 sessions. The median delay between each session was 2 days (1-4).

\section{Effects of prone position session on respiratory state}

Pre-PP parameters are described in Table 2. Twentyseven sessions were performed. All sessions had an identical duration of $24 \mathrm{~h}$. In 23/27 sessions, nurses described a major increase in sputum drainage. After $24 \mathrm{~h}$ in PP under the same respiratory and ECMO settings, $\mathrm{PaO}_{2} /$ $\mathrm{FiO}_{2}$ increased from $111(84-128)$ to 173 (120-203) $\mathrm{mmHg}(p<0.0001)$ (Fig. 1). $\mathrm{PaO}_{2} / \mathrm{FiO}_{2}$ increased by more than $20 \%$ in $22 / 27$ sessions. According to this threshold value, when PP was performed after day $7, \mathrm{PaO}_{2} / \mathrm{FiO}_{2}$ ratio increased by more than $20 \%$ in $14 / 14$ sessions. Conversely, only $7 / 12$ sessions had a higher than $20 \%$ increase in $\mathrm{PaO}_{2} / \mathrm{FiO}_{2}$ ratio before day $7(p=0.01)$. RS compliance significantly increased after $24 \mathrm{~h}$ in PP from 18 (12-36) to $32(15-36) \mathrm{ml} / \mathrm{cmH}_{2} \mathrm{O}(p<0.005)$ (Fig. 2). Additional file 4: Figure S2 and Additional file 5: Figure S3 (see supplemental digital content) provide individual data for plateau pressure and RS compliance, respectively. Twenty-four

Table 2 Baseline characteristics

\begin{tabular}{|c|c|}
\hline $\mathrm{PaO}_{2} / \mathrm{FiO}_{2}(\mathrm{mmHg})$ & $111(84-128)$ \\
\hline $\mathrm{PaCO}_{2}(\mathrm{mmHg})$ & $42(39-43)$ \\
\hline Tidal volume (ml/kg) & $3.0(2.2-4.0)$ \\
\hline Arterial pH & $7.42(7.39-7.44)$ \\
\hline $\operatorname{PEEP}\left(\mathrm{cmH}_{2} \mathrm{O}\right)$ & $12(6-13)$ \\
\hline Plateau pressure $\left(\mathrm{cmH}_{2} \mathrm{O}\right)$ & $24(22-25)$ \\
\hline RS compliance $\left(\mathrm{ml} / \mathrm{cmH}_{2} \mathrm{O}\right)$ & $18(12-36)$ \\
\hline Respiratory frequency (cycles/min) & $17(10-25)$ \\
\hline \multicolumn{2}{|l|}{ ECMO settings } \\
\hline $\mathrm{FiO}_{2}(\%)$ & $70(70-90)$ \\
\hline ECMO blood flow (l/min) & $4.7(3.7-5.5)$ \\
\hline Sweep gas (I/min) & $5.0(3.0-5.0)$ \\
\hline
\end{tabular}



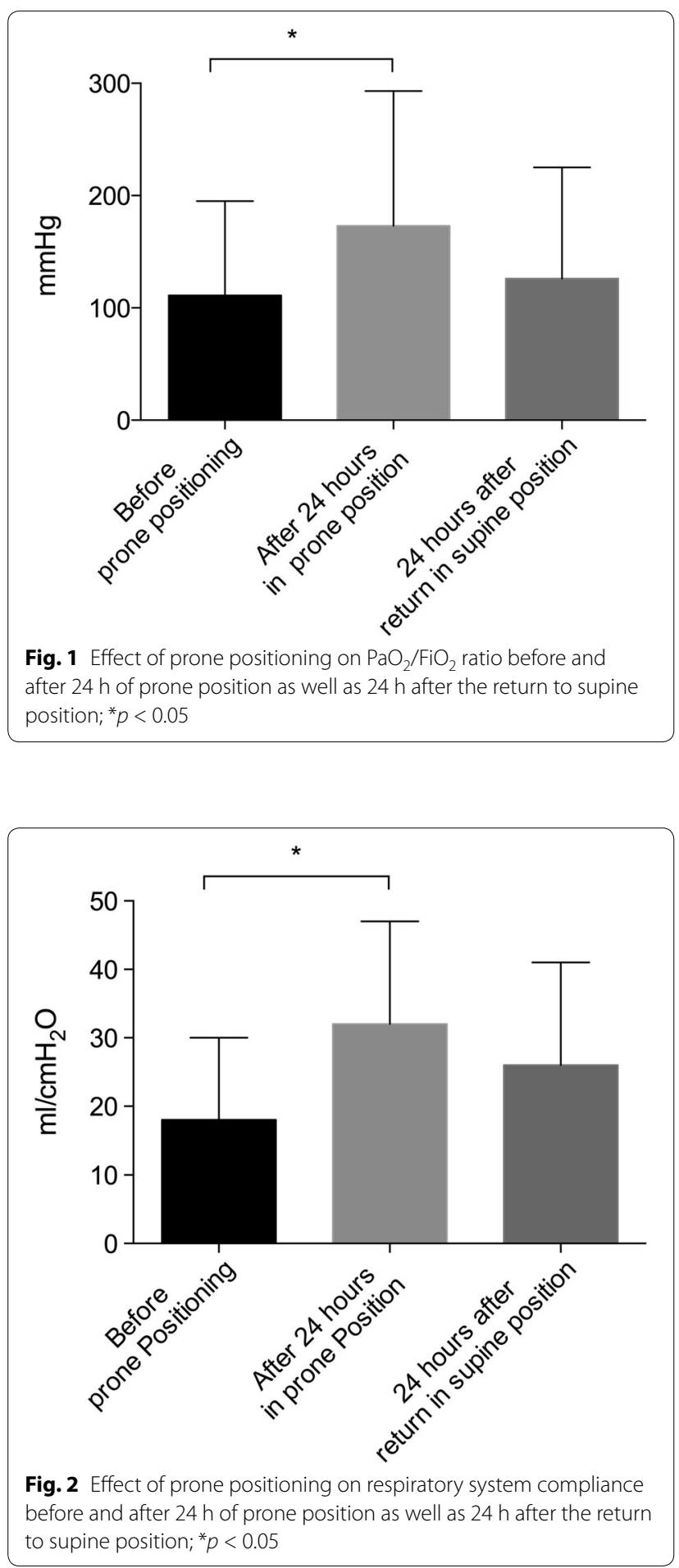

hours after the return to supine position, tidal volume was significantly increased from $3(2.2-4)$ before PP to 3.7 $(2.8-5) \mathrm{ml} / \mathrm{kg}$ of predicted body weight $(p<0.05)$. Arterial $\mathrm{PCO}_{2}$ did not change during and after PP.

\section{Correlation between lung condensation and $\mathrm{PaO}_{2} / \mathrm{FiO}_{2}$ response}

Fifteen CT scans were performed prior to placement in prone position. All patients exhibited a high percentage of non-aerated or poorly-aerated lung parenchyma prior to PP: $52 \%$ (41-62). Thus, no correlation was found between the increase in $\mathrm{PaO}_{2} / \mathrm{FiO}_{2}$ ratio and the amount of non-aerated lung tissue measured on chest scans $(r=0.064, p=0.82)$.

\section{Adverse events attributable to PP}

In one patient, an oxygenator thrombosis occurred while one other patient required fluid resuscitation in order to correct a drop in VV-ECMO flow.

No adverse event was related to either the tracheal tube, the ventilator device or other catheters.

\section{Discussion}

The main findings of the present study are that (1) in a majority of patients, PP markedly improved oxygenation during VV-ECMO and was not associated with side effects confirming the Guervilly et al. study, (2) the improvement in oxygenation appeared to be more efficient when applied after 7 days of VV-ECMO, (3) contrary to the Guervilly et al. study, PP was associated with an improvement in lung compliance therefore allowing the use of increased Vt and (4) there was no correlation between the volume of condensation and PP efficiency.

Prone positioning during VV-ECMO improves oxygenation All currently published studies are consistent with regard to the effect of PP on oxygenation during VVECMO. Clearly, PP improves oxygenation in a majority of patients. Moreover, previous studies mainly studied the effects of PP when performed late after VV-ECMO initiation ( 8 days in the Guervilly et al. study). It appears that for some patients PP was effective under ECMO and ineffective prior to ECMO. It is likely that time is an important factor in allowing lung healing and symptomatic treatments such as antibiotics to be effective. The decrease in lung aggression secondary to ultraprotective ventilation should also be considered.

\section{Prone positioning during VV-ECMO improves respiratory} system compliance and allows increased tidal volume Importantly, PP was associated with a marked decrease in plateau pressure in patients in whom it was not possible to maintain this pressure under $25 \mathrm{cmH}_{2} \mathrm{O}$. In randomized controlled trials comparing supine and prone positions, the results on respiratory compliance have been inconsistent. Indeed, Mancebo et al. noted higher compliance of the respiratory system in the prone 
position, whereas Guerin et al. and Taccone et al. did not $[20,21]$. Previous studies using PP during VV-ECMO also failed to demonstrate any significant changes in static compliance. Guervilly et al. suggested that the improvement in oxygenation without concomitant increase in respiratory static compliance and without decrease in $\mathrm{PaCO}_{2}$ at constant levels of minute ventilation and sweep gas flow do not suggest lung recruitment by PP with relatively small $\mathrm{Vt}$ and high levels of PEEP but rather an improvement in VA/Q mismatch. Unfortunately, no CT scan data were provided in their study. Herein, all of our patients had major posterior condensation $(>50 \%$ of lung volume) and thus it is likely that PP in this situation allows lung recruitment. Arguing in favor of this hypothesis is the fact that PP further allows the use of increased Vt. Importantly, in 23/27 sessions, nurses described a major increase in sputum drainage that may have contributed to recruitment. Another hypothesis to explain this discrepancy is that prolonged PP sessions were used in our study ( $24 \mathrm{~h}$ as opposed to $12 \mathrm{~h}$ ), which may have contributed to the observed improvement in compliance. Finally, the discrepancy could be due to different patient populations, i.e. patients still under sedation in whom it was not possible to use partial mode of ventilatory support or to a different phase of the disease comparatively to previous reports.

The driving pressure (plateau pressure minus PEEP) is associated with ARDS prognosis, [14] but also with treatment efficiency when associated with decreases in $\Delta P$. Interestingly, the driving pressure observed in our study was relatively low and the use of PP was associated with a further decrease in driving pressure.

\section{Study limitations}

Although the present constitutes the largest study relative to the use of PP during VV-ECMO, the number of studied patients remains relatively small. Nevertheless, severe ARDS treated with ECMO and needing prone positioning is a rare occurrence and thus it is unlikely that a multicenter randomized study will be performed. Accordingly, only 36 cases have been previously reported in the literature in which session durations differed considerably. Therefore, we firmly believe that this study adds valuable information, first in confirming previous but scarce data but also in extending these data with new findings, notably on compliance.

The small sample size may also have had a bearing on our findings regarding the comparison between early and late sessions. In addition, specific predefined criteria were chosen as to whether or not to use PP in our VVECMO patients. Therefore, our results and conclusions are only valuable when considering the present clinical algorithm. Finally, because of the retrospective nature of the present study, it was not possible to study the mechanism involved in PP effects during VV-ECMO.

\section{Conclusions}

When used in combination with VV-ECMO, $24 \mathrm{~h}$ of prone positioning improves both oxygenation and respiratory system compliance. Moreover, our study confirms the absence of serious adverse events. Currently, it remains unknown when and for which indication prone positioning should be systematically applied during VV-ECMO. Therefore, further studies are needed to better delineate prone positioning indications during VV-ECMO.

\section{Additional files}

Additional file 1: Movie S1 Protocol for prone positioning under WECMO (Supplemental Digital Content movie).

Additional file 2: Protocol for prone positioning under W-ECMO (Supplemental Digital Content movie).

Additional file 3: Figure S1. CT scan analysis. In a first step in the analysis of CT images (A), lung contours were manually delineated from chest wall, mediastinum and pleural effusion. This resulted in the crude lung volume (B). (Actual, True) lung volume (C) was obtained by excluding large vessels (densities above $150 \mathrm{HU}$ on enhanced scans) and bronchi lumen and hyperinflated lungs (densities below $900 \mathrm{HU}$ ). Lastly, a normallyaerated lung was defined as having a density below $100 \mathrm{HU}$ (D).

Additional file 4: Figure S2. Evolution of plateau pressure before and $24 \mathrm{~h}$ after prone positioning. Individual data.

Additional file 5: Figure S3. Evolution of respiratory system compliance before and $24 \mathrm{~h}$ after prone positioning. Individual data.

\section{Authors' contributions}

AK supervised development of the work, performed data interpretation and wrote the manuscript; SR recorded data and performed data interpretation; $\mathrm{CB}$ wrote the prone-positioning procedure; FV helped in data interpretation and manuscript evaluation; DM performed CT scan analysis and wrote CT scan methodology; NG and RF performed the statistical analysis; BL supervised development of the work, helped in data interpretation and manuscript evaluation and wrote the manuscript. All authors read and approved the final manuscript.

\section{Author details}

${ }^{1}$ CHU Nancy, Service de Réanimation Médicale Brabois, Pole Cardiovasculaire et Réanimation Médicale, Hôpital Brabois, 54511 Vandoeuvre les Nancy, France. ${ }^{2}$ INSERM U 1116, Groupe Choc, Equipe 2, Faculté de Médecine, 54511 Vandoeuvre les Nancy, France. ${ }^{3}$ Université de Lorraine, 54000 Nancy, France. ${ }^{4}$ CHU Nancy, Département de Radiologie, Hôpital Brabois, 54511 Vandoeuvre les Nancy, France. ${ }^{5}$ CHU Nancy, Département de Chirugie Cardiaque Brabois, Pole Cardiovasculaire et Réanimation Médicale, Hôpital Brabois, 54511 Vandoeuvre les Nancy, France. ${ }^{6}$ INSERM, Centre d'Investigations Cliniques-9501 and CHU de Nancy, 54511 Vandoeuvre les Nancy, France.

\section{Acknowledgements}

We thank Pierre Pothier for the English manuscript proofreading service.

\section{Competing interests}

The authors declare that they have no competing interests.

Received: 8 July 2015 Accepted: 21 October 2015

Published online: 04 November 2015 


\section{References}

1. Guerin C, Reignier J, Richard JC, Beuret P, Gacouin A, Boulain T, Mercier E, Badet M, Mercat A, Baudin O, Clavel M, Chatellier D, Jaber S, Rosselli S, Mancebo J, Sirodot M, Hilbert G, Bengler C, Richecoeur J, Gainnier M, Bayle F, Bourdin G, Leray V, Girard R, Baboi L, Ayzac L, Group PS. Prone positioning in severe acute respiratory distress syndrome. N Engl J Med. 2013;368:2159-68.

2. Peek GJ, Mugford M, Tiruvoipati R, Wilson A, Allen E, Thalanany MM, Hibbert CL, Truesdale A, Clemens F, Cooper N, Firmin RK, Elbourne D. CESAR trial collaboration. Efficacy and economic assessment of conventional ventilatory support versus extracorporeal membrane oxygenation for severe adult respiratory failure (CESAR): a multicentre randomised controlled trial. Lancet. 2009:374:1351-63.

3. Schmidt M, Zogheib E, Roze H, Repesse X, Lebreton G, Luyt CE, Trouillet $J$, Brechot N, Nieszkowska A, Dupont H, Ouattara A, Leprince P, Chastre J, Combes A. The PRESERVE mortality risk score and analysis of long-term outcomes after extracorporeal membrane oxygenation for severe acute respiratory distress syndrome. Intensive Care Med. 2013;39:1704-13.

4. Parhar K, Vuylsteke A. What's new in ECMO: scoring the bad indications. Intensive Care Med. 2014:40:1734-7.

5. Levy B, Taccone FS, Guarracino F. Recent developments in the management of persistent hypoxemia under veno-venous ECMO. Intensive Care Med. 2015;41(3):508-10.

6. Kimmoun A, Guerci P, Bridey C, Ducrocq N, Vanhuyse F, Levy B. Prone positioning use to hasten veno-venous ECMO weaning in ARDS. Intensive Care Med. 2013;39:1877-9.

7. Guervilly C, Hraiech S, Gariboldi V, Xeridat F, Dizier S, Toesca R, Forel JM, Adda M, Grisoli D, Collart F, Roch A, Papazian L. Prone positioning during veno-venous extracorporeal membrane oxygenation for severe acute respiratory distress syndrome in adults. Minerva Anestesiol. 2014;80:307-13.

8. Kipping V, Weber-Carstens S, Lojewski C, Feldmann P, Rydlewski A, Boemke W, Spies C, Kastrup M, Kaisers UX, Wernecke KD, Deja M. Prone position during ECMO is safe and improves oxygenation. Int J Artif Organs. 2013;36:821-32.

9. Kredel M, Bischof L, Wurmb TE, Roewer N, Muellenbach RM. Combination of positioning therapy and venovenous extracorporeal membrane oxygenation in ARDS patients. Perfusion. 2014;29:171-7.

10. Masuda Y, Tatsumi H, Imaizumi H, Gotoh K, Yoshida S, Chihara S, Takahashi $\mathrm{K}$, Yamakage M. Effect of prone positioning on cannula function and impaired oxygenation during extracorporeal circulation. J Artif Organs. 2014;17:106-9.

11. Otterspoor LC, Smit FH, van Laar TJ, Kesecioglu J, van Dijk D. Prolonged use of extracorporeal membrane oxygenation combined with prone positioning in patients with acute respiratory distress syndrome and invasive Aspergillosis. Perfusion. 2012:27:335-7.
12. Force ADT, Ranieri VM, Rubenfeld GD, Thompson BT, Ferguson ND, Caldwell E, Fan E, Camporota L, Slutsky AS. Acute respiratory distress syndrome: the Berlin Definition. JAMA. 2012;307:2526-33.

13. Schmidt M, Tachon G, Devilliers C, Muller G, Hekimian G, Brechot N, Merceron S, Luyt CE, Trouillet JL, Chastre J, Leprince P, Combes A. Blood oxygenation and decarboxylation determinants during venovenous ECMO for respiratory failure in adults. Intensive Care Med. 2013;39:838-46.

14. Amato MB, Meade MO, Slutsky AS, Brochard L, Costa EL, Schoenfeld DA, Stewart TE, Briel M, Talmor D, Mercat A, Richard JC, Carvalho CR, Brower RG. Driving pressure and survival in the acute respiratory distress syndrome. N Engl J Med. 2015:372:747-55.

15. Schmidt M, Bailey M, Sheldrake J, Hodgson C, Aubron C, Rycus PT, Scheinkestel C, Cooper DJ, Brodie D, Pellegrino V, Combes A, Pilcher D. Predicting survival after extracorporeal membrane oxygenation for severe acute respiratory failure. The Respiratory Extracorporeal Membrane Oxygenation Survival Prediction (RESP) score. Am J Respir Crit Care Med. 2014;189:1374-82

16. Malbouisson LM, Muller JC, Constantin JM, Lu Q, Puybasset L, Rouby JJ. Group CTSAS. Computed tomography assessment of positive end-expiratory pressure-induced alveolar recruitment in patients with acute respiratory distress syndrome. Am J Respir Crit Care Med. 2001;163:1444-50.

17. Protti A, Chiumello D, Cressoni M, Carlesso E, Mietto C, Berto V, Lazzerini M, Quintel M, Gattinoni L. Relationship between gas exchange response to prone position and lung recruitability during acute respiratory failure. Intensive Care Med. 2009;35:1011-7.

18. Albert RK, Keniston A, Baboi L, Ayzac L, Guerin C. Prone position-induced improvement in gas exchange does not predict improved survival in the acute respiratory distress syndrome. Am J Respir Crit Care Med. 2014;189:494-6.

19. Ferguson ND, Fan E, Camporota L, Antonelli M, Anzueto A, Beale R, Brochard L, Brower R, Esteban A, Gattinoni L, Rhodes A, Slutsky AS, Vincent JL, Rubenfeld GD, Thompson BT, Ranieri VM. The Berlin definition of ARDS: an expanded rationale, justification, and supplementary material. Intensive Care Med. 2012;38:1573-82.

20. Mancebo J, Fernandez R, Blanch L, Rialp G, Gordo F, Ferrer M, Rodriguez F, Garro P, Ricart P, Vallverdu I, Gich I, Castano J, Saura P, Dominguez G, Bonet A, Albert RK. A multicenter trial of prolonged prone ventilation in severe acute respiratory distress syndrome. Am J Respir Crit Care Med. 2006;173:1233-9.

21. Taccone P, Pesenti A, Latini R, Polli F, Vagginelli F, Mietto C, Caspani L, Raimondi F, Bordone G, lapichino G, Mancebo J, Guerin C, Ayzac L, Blanch L, Fumagalli R, Tognoni G, Gattinoni L, Prone-Supine IISG. Prone positioning in patients with moderate and severe acute respiratory distress syndrome: a randomized controlled trial. JAMA. 2009;302:1977-84.

\section{Submit your manuscript to a SpringerOpen ${ }^{\circ}$ journal and benefit from:}

- Convenient online submission

- Rigorous peer review

- Immediate publication on acceptance

- Open access: articles freely available online

- High visibility within the field

- Retaining the copyright to your article

Submit your next manuscript at $>$ springeropen.com 